\title{
THE PREVALENCE OF ENDOCRINOPATHIES AMONG PATIENTS WITH THALASSEMIA MAJOR IN THE DISTRICT OF BATTICALOA, SRI LANKA
}

\section{Dharshini Karuppiah", S Thimbirigaha Arawa1, J Sivaganam¹, V Thirukumar², A Arul Pragasam², K Sivakanthan ${ }^{2}$}

1 Diabetes and Endocrinology unit, Teaching Hospital Batticaloa.

2 Paediatric unit, Teaching Hospital Batticaloa.

\section{ABSTRACT}

Introduction: Thalassaemia major is an inherited haemoglobinopathy characterised by chronic anaemia. Excessive iron overload and suboptimal chelation result in deposition of iron in various tissues including endocrine glands.

Objective: To estimate the prevalence of endocrinopthies in patients with thalassemia major among patients attending clinics at Teaching Hospital Batticaloa.

Materials and Methods: Cross sectional descriptive study of patients with thalassemia major on active follow up from June 2015 to 2016 at Teaching Hospital Batticaloa. Height, weight, and tanner staging, serum ferritin, oral glucose tolerance test, bone profile, liver and renal function, thyroid function, cortisol for all patients and FSH, LH, testosterone or oestradiol for girls over 13 years of age and boys over 14 years of age were assessed.

Results: A total of 95 patients including 50 females with the mean age of $11.83 \pm 4.53$ years were evaluated. Shortstature was found in 55(57.8\%). Hypocalcaemia was present in $36(37.8 \%)$ and $24(25 \%)$ had hypothyroidism. Diabetes mellitus and impaired glucose tolerance (IGT) were found in 7(7.4\%) and 13(13.2\%) respectively. Only $2(2.1 \%)$ had cortisol deficiency. Among girls over 13 and boys over 14 years of age, 33(78.6\%) had hypogonadism. Sixty six patients with mean serum ferritin level above $2500 \mathrm{ng} / \mathrm{mL}$ had higher incidence of hypocalcaemia, hypothyroidism, hypogonadism, and short stature $(28$ vs $5 ; \mathrm{p}=0.004,18$ vs 6;p=0.048, 28 vs $5 ; p=0.03$, and 39 vs $16 ; p=0.054$ respectively) than those who had less than $2500 \mathrm{ng} / \mathrm{mL}$. Patients who were above 9 years of age had higher incidence of hypocalcaemia ( 32 vs $2 ; p=0.00)$, short stature ( 33 vs $22 ; p=0.026)$, and IGT (11 vs $2 ; p=0.017$ ) when compared to younger patients.

Conclusions: A significant proportion of thalassemia major patients have endocrinopathies. Hypothyroidism and short stature develop very early and other endocrinopathies also develop earlier indicating the need for early screening compared to the recommended guidelines. As the duration of thalassemia increases the risk for developing endocrinopathies is high.

Key Words: Thalassaemia major, endocrinopathy, diabetes mellitus and risk factors.

\section{INTRODUCTION}

Thalassaemia major is a severe autosomal recessive haemolytic anaemia caused by absence or marked deficiency of the beta globin chain of haemoglobin. The homozygous state results in severe anaemia which requires frequent blood transfusions. This, along with increased rate of iron absorption in the gut causes iron overload. Excessive iron overload due to suboptimal chelation result in deposition of iron in various tissues, primarily heart and liver and frequently involves endocrine glands. Chronic hypoxia due to anaemia, viral infections and individual susceptibility are other factors which could potentiate the toxicity of iron deposition, contributing to endocrine dysfunction $(1,2)$. Available data show the leading endocrine complications among patients with thalassaemia are growth retardation, hypogonadism, diabetes mellitus, hypothyroidism, hypoparathyroidism, osteoporosis and adrenal insufficiency (3).

In addition to iron overload, poor nutrition, chronic anaemia, chelating agents, liver disease, and genetic susceptibility are the other factors which have been linked to slow growth and endocrinopathies in patients with thalassaemia (4). As the prevention of thalassaemia related endocrinepathies remains a challenge, regular screening is recommended. However, it is not clear when this process should start 
or what is the best procedure for conducting it, as the age of onset of these endocrinopathies is not well defined. Hence there is a need for estimating the prevalence of common endocrinopathies in patients with Thalassaemia and risk factors for developing these complications, among Sri Lankan population. Therefore, we designed this study to estimate the prevalence of common endocrinopathies in patients with Thalassaemia major who were followed up at Teaching hospital, Batticaloa.

\section{METHODOLOGY}

This is a descriptive cross sectional study. The study subjects were all patients with diagnosed Thalassaemia major on regular blood transfusion for more than 2 years duration, who were attending paediatric, heamatology and endocrinology clinics at Teaching Hospital Batticaloa.

All patients who have full filled the selection criteria and given consent were included. Diagnosed patients with thalassaemia intermedia, thalassaemia minor, other haemoglobinopathies and other haemolytic anaemia were excluded from the study.

The study was approved by the ethical committee of eastern university and permission from the director, Teaching Hospital Batticaloa was obtained for utilising the data and conducting the study. All participants were given assurance that their identity will not be revealed and personnel information could be kept confidential. Informed written consent was obtained from all patients, their parents or guardians if participants are younger than 16 years.

Demographic data, details of disease management (duration and age at the start of transfusion and chelation), and auxological details (height, weight, tanner staging for pubertal development) were recorded in a data collection form by the trained medical officer.

The following hormonal assessment were done: TSH, freeT4, 9am cortisol for all patents and FSH, LH, prolactin, oestradiol or testosterone for girls over 13 years of age and boys over 14 years of age.

Biochemical assessment including oral glucose tolerance test (OGTT) using 75g glucose, serum calcium, phosphate, alkaline phosphatase, haemoglobin, mean serum ferritin, renal function, liver enzymes and liver function were taken.

\section{Description of endocrinopathy (5)}

- $\quad$ Short stature was defined as height below the third percentile and below the mid-parental height centile on the CDC growth chart.

- Delayed puberty was defined as absence of breast development by the age of 13 years in girls or absence of genital development (testicular volume less than $4 \mathrm{ml}$ ) at 14 years in boys. Incomplete puberty is defined as primary amenorrhea in females at 17 years or failure to reach Tanner genitalia stage 5 in males by the age of 18 years.

- Patients with hypogonadism (delayed or incomplete puberty) and prepubertal basal follicular stimulating hormone (FSH) and luteinizing hormone ( $\mathrm{LH})$ levels were considered to have hypogonadotrophic hypogonadism, and those with high basal FSH and LH levels were defined as having gonadal failure.

- Primary hypothyroidism was defined as subnormal free thyroxin (FT4) with raised thyroid stimulating hormone (TSH), subclinical hypothyroidism as normal FT4 with high TSH (5-10miu/l) and secondary hypothyroidism as subnormal FT4 with normal or subnormal TSH on more than 2 consecutive occasions.

- Hypoparathyroidism was defined as subnormal serum calcium with high phosphate with subnormal or inappropriately low parathyroid hormone (PTH) level.

- Patients were considered to have diabetes if their fasting glucose more than $126 \mathrm{mg} / \mathrm{dl}$ and / or 2 hour post glucose level more than $200 \mathrm{mg} / \mathrm{dl}$. Impaired glucose tolerance was defined as 2 hour post glucose level of 140$199 \mathrm{mg} / \mathrm{dl}$ and impaired fasting glucose when fasting glucose level of $100-125 \mathrm{mg} / \mathrm{dl}$.

- Adrenal insufficiency was defined as morning (9 am) serum cortisol less than $150 \mathrm{nmol} / \mathrm{L}$ with or without abnormal serum sodium and potassium.

The data were analyzed using SPSS Statistical Software Package.

All numerical data were expressed as mean and standard error of mean $( \pm$ SEM). Correlation among variables was assessed using Chi square test. Statistical significance is described when p-value less than 0.05 . 
Table1: Demographic, auxological and biochemical variables of patients with thalassaemia major attending to Teaching Hospital Batticaloa, Sri Lanka.

\begin{tabular}{|llll|}
\hline Variable & Mean+/- SD & 95\% CI & Standard error \\
\hline Age (Y) & $11.83+/-4.53$ & $10.83-12.83$ & 0.50 \\
Weight (Kg) & $26.58+/-9.51$ & $24.48-28.68$ & 1.05 \\
Height (cm) & $130.74+/-16.67$ & $127.06-134.43$ & 1.85 \\
Ferritin level (ng/ml) & $4083.3+/-2592.89$ & $3509.96-4656.63$ & 288.09 \\
$\begin{array}{l}\text { Duration of thalassaemia } \\
\text { (Y) }\end{array}$ & $10.42+/-4.33$ & $9.46-11.38$ & 0.48 \\
\hline
\end{tabular}

\section{RESULTS}

A total of 95 patients including 50 females and 45 males with mean age of $11.83 \pm 4.53$ years were evaluated. The characteristics of the patients are shown in table 1.The prevalence of endocrinopathies was shown in table 2 and 3. Short stature was found in 55 (57.8\%). Among 42 patients who were evaluated for pubertal development, 33 (78.6\%) had hypogonadism, and all were proven to be hypogonadotrpic hypogonadism. Hypocalcaemia was present in 34 (35.7\%) and 24 (25.2\%) had hypothyroidism. Diabetes mellitus and impaired glucose tolerance (IGT) were found in 7 (7.4\%) and 13 (13.6\%) respectively. Only 2 (2.1\%) had cortisol deficiency.

Among this sample, the youngest age for patients with endocrinopathies were as follows (table 4): hypothyroidism; 3years, short stature; 5years, hypocalcaemia; 9years, IGT;9 years, diabetes;10years and cortisol deficiency;14years.

Sixty six patients with mean serum ferritin level above $2500 \mathrm{ng} / \mathrm{mL}$ had higher incidence of hypocalcaemia than those who had less than $2500 \mathrm{ng} / \mathrm{mL}$ (28 vs 5, $\mathrm{p}=0.004$ ). Higher prevalence of hypothyroidism, hypogonadism, and short stature (18 vs $6 ; \mathrm{p}=0.048,28$ vs $5 ; \mathrm{p}=0.03$, and 39 vs $16 ; \mathrm{p}=0.054$ respectively) was noted among patients with ferritin levels above 2500ng/mL.

Patients who were above 9 years of age had higher incidence of hypocalcaemia (32 vs $2 ; \mathrm{p}=0.00$ ), short stature (33 vs 22; $=0.026$ ), and IGT (11 vs 2 ; $\mathrm{p}=$ when compared to younger patients (0.017) . Although statistically not significant, prevalence of hypothyroidism (16 vs 8; p=0.085), and cortisol deficiency ( 2 vs $0 ; \mathrm{p}=0.118$ ) were higher among patients with longer duration of disease.

\section{DISCUSSION}

Thalassemia patients have a high prevalence of endocrinological abnormalities. Our study revealed that a significant proportion of thalassaemia major patients have endocrinopathies (table 2). The international network on endocrine complications in thalassemia (I-CET) position statement and guidelines recommend annual endocrine screening from the age of 9 years and earlier if clinically suspecting short stature. In our sample the youngest age of patient with endocrinopathies were shown in table 2. Although majority of children develop endocrine disorders after 9 years, 9 (9.4\%) were younger than 9 years with either short stature or hypothyroidism. Growth retardation is commonly reported in children and adolescents with thalassaemia. The pathogenesis of growth failure is multifactorial including transfusion-related iron overload, chelation toxicity and other contributing endocrine disorders such as hypothyroidism, hypogonadism, growth hormone deficiency or insufficiency, zinc deficiency, chronic liver disease, under nutrition, and psychosocial stress $(2,6,7)$. Our study showed $71(75 \%)$ were having body weight less than $3^{\text {rd }}$ centile, and 55(57.5\%) of children had height below the $3^{\text {rd }}$ centile and below the mid-parental height centile on CDC growth chart. The limitations on using this charts for defining short stature should be considered in our population. This is due to the fact that a significant proportion of normal children are below $3^{\text {rd }}$ centile. Therefore mid-parental height should be taken when defining short stature. In addition, the duration of thalassaemia was significantly associated with short stature. This is probably due to iron overload and failure of gaining their pubertal growth spurt. In our study $8(14.5 \%)$ were younger than 9 years old and the youngest was 5 years old. 
Table 2: Comparison of prevalence of endocrinopathies between those with serum ferritin above $2500 \mathrm{ng} / \mathrm{mL}$ and below $2500 \mathrm{ng} / \mathrm{mL}$ among thalassemia patients attending to Teaching Hospital Batticaloa, Sri Lanka.

\begin{tabular}{|lllll|}
\hline Endocrinopathies & $\begin{array}{l}\text { No of patients with } \\
\text { Ferritin>2500ng/mL }\end{array}$ & $\begin{array}{l}\text { No of patients with } \\
\text { Ferritin<2500ng/mL }\end{array}$ & $\begin{array}{l}\text { Total No of } \\
\text { patients (\%) }\end{array}$ & $\begin{array}{l}\text { P value (Pearson } \\
\text { Chi Square) }\end{array}$ \\
\hline Hypocalcaemia & 28 & 5 & $34(35.7 \%)$ & 0.004 \\
Hypothyroidism & 18 & 6 & $24(25.2 \%)$ & 0.048 \\
Hypogonadism & 28 & 5 & $33(78.6 \%)$ & 0.03 \\
Short stature & 39 & 16 & $55(57.8 \%)$ & 0.054 \\
IGT & 11 & 2 & $13(13.6 \%)$ & 0.13 \\
DM & 5 & 2 & $7(7.4 \%)$ & 0.95 \\
Cortisol deficiency & 2 & 0 & $2(2.1 \%)$ & 0.65 \\
\hline
\end{tabular}

Table 3 - Comparison of prevalence of endocrinopathies between those who are above 9 years and below 9 years of age among thalassemia patients attending teaching hospital Batticaloa, Sri Lanka.

\begin{tabular}{|l|l|l|l|l|}
\hline Endocrinopathies & $\begin{array}{l}\text { No of patients with } \\
\text { age } \mathbf{9} \text { years }\end{array}$ & $\begin{array}{l}\text { No of patients with } \\
\text { age < 9 years }\end{array}$ & $\begin{array}{l}\text { Total No of } \\
\text { patients (\%) }\end{array}$ & $\begin{array}{l}\text { P value } \\
\text { (Pearson Chi } \\
\text { Square) }\end{array}$ \\
\hline $\begin{array}{l}\text { Hypocalcaemia } \\
\text { Hypothyroidism }\end{array}$ & 32 & 2 & $34(35.7 \%)$ & 0.000 \\
$\begin{array}{l}\text { Short stature } \\
\text { IGT }\end{array}$ & 16 & 8 & $24(25.2 \%)$ & 0.085 \\
Cortisol deficiency & 33 & 22 & $55(57.8 \%)$ & 0.026 \\
\hline
\end{tabular}

Table 4 - Youngest age in the sample of patients with thalassaemia major attending to Teaching Hospital Batticaloa, Sri Lanka.

\begin{tabular}{|l|l|}
\hline Endocrinopathy & Youngest Age (Y) \\
\hline Hypothyroidism & 3 \\
Short stature & 5 \\
Hypocalcaemia & 9 \\
IGT & 9 \\
DM & 10 \\
Cortisol deficiency & 14 \\
\hline $\begin{array}{l}\text { One fourth of our patients had hypothyroidism. In our } \\
\text { study, some patients were already treated with }\end{array}$ & \begin{tabular}{l} 
geed for early screening compared to the recommended \\
\hline
\end{tabular}
\end{tabular}
thyroxine based on elevated TSH or subnormal FT4 alone. Therefore we were unable to subcategorize the diagnosis as primary, secondary or subclinical hypothyroidism. Similar studies showed that majority of patients were diagnosed with primary hypothyroidism and secondary hypothyroidism seen only in $3.5 \%(8,9)$. The I-CET position statement and guidelines recommend annual investigation of thyroid function beginning at the age of 9 years (10). In our study 4 (16.6\%) patients were below 9 years old when diagnosed with hypothyroidism and the youngest patients was 3 years of age. Hypothyroidism and short stature develop early in our population indicating the
Hypoparathyroidism is considered as an uncommon complication and usually presents after the age of 16 years (10). In contrary to this we found a significant proportion 34 (35.7\%) was complicated with hypocalcaemia and hyperphosphataemia suggestive of hypoparathyroidism and the youngest age was 9 years in our sample. The majority of the patients was asymptomatic or presented with mild symptoms. Hypoparathyroidism is thought to be the consequence of iron deposition in the parathyroid glands or due to suppression of parathyroid secretion induced by bone reabsorption resulting from increased hematopoiesis secondary to the chronic anaemia $(11,12)$. High serum 
ferritin levels and the longer duration of thalassaemia were significantly associated with hypocalcaemia in this study.

Diabetes and impaired glucose tolerance (IGT) are relatively common complications among inadequately chelated patients. As life expectancy in patients with thalassaemia rises, diabetic complications are commonly seen. The prevalence of diabetes mellitus in patients with thalassaemia major ranges from 6.4 to $14.1 \%$ in cross sectional studies (13). This current study showed presence of Diabetes mellitus and IGT in $7.4 \%$ and $13.6 \%$ respectively. Patients with thalassaemia could develop diabetes secondary to their illness and complications of therapy. Likewise, with the worldwide epidemic of diabetes, they could develop type 1 or type 2 diabetes, independently of their thalassaemia status $(14,15)$.

Although clinical adrenal crisis is extremely rare, several studies reported a significant prevalence of biochemical adrenal insufficiency, ranging from $0 \%$ to $45 \%$, in patients with thalassaemia. The wide variation is due to different patient characteristics and different diagnostic tests used $(16,17)$. Only 2 patients $(2.1 \%)$ had cortisol deficiency in this study. Patients are usually asymptomatic but this could be masked by symptoms commonly complained by thalassemic patients, such as myalgias, arthralgias and weight loss. In addition to cortisol deficiency, adrenal androgen levels might be decreased explaining the poor development of pubic and axillary hair observed in thalassemic adolescents $(16,17)$.

Comparable to other studies hypogonadism was the most common endocrinopathy in our patients (18-21). Out of 42 patients (28 female and 14 males) who were evaluated for pubertal development, the overall prevalence of hypogonadism was $78.6 \%$, including $71 \%$ of girls and $92 \%$ of boys. All our patients had secondary hypogonadism with low basal FSH and LH indicating hypothalamic-pituitary damage. This is likely to be secondary to iron deposition on gonadotrophic cells of the pituitary gland (22-24). Among patients with thalassaemia major, an impact of the genotype on gonadal function also has been documented (25).

A significant proportion of thalassaemia major patients have endocrinopathies. . The longer the duration of thalassaemia, the higher the risk for developing endocrinopathies. Hypothyroidism and short stature develop early and other endocrinopathies develop after 9 years of age, indicating the need for earlier screening compared to the recommended guidelines. For early detection, regular follow-up is essential. Treatment of endocrine disorders in patients with thalassaemia is an additional burden, support from family, health care providers and psychologists are needed. Multidisciplinary team with patient centered approach will be the way forward. Joint clinic where members of both endocrinology and thalassaemia teams work together with patients will be a better option to manage these patients with complex needs. This also allows staff to learn from each other and provide a consistent approach towards every patient.

\section{FUNDING}

This research did not receive any specific grant from any funding agency in the public, commercial or notfor-profit sector.

\section{DECLARATION OF INTEREST}

There is no conflict of interest that could be perceived as prejudicing the impartiality of the research reported.

\section{ACKNOWLEDGEMENTS}

Santharuben (Eastern university of SriLanka), for the support on statistical analysis.

\section{REFERENCES}

1. Magro S, Puzzonia P, Consarino C, et al. Hypothyroidism in patients with thalassaemia syndromes. Acta Haematologica 1990; 84:72-6.

2. De Sanctis V. Growth and puberty and its management in thalassaemia. Hormone Research 2002; 58:72-9.

3. Delvecchio M, Cavallo L. Growth and endocrine function in thalassemia major in childhood and adolescence. Journal of Endocrinological Investigation 2010; 33(1):61-8.

4. De Sanctis V, Eleftheriou A, Malaventura C; Thalassaemia International Federation Study Group on Growth and Endocrine Complications in Thalassaemia. Prevalence of endocrine complications and short stature in patients with thalassaemia major: a multicenter study by the Thalassaemia International Federation (TIF). Pediatric Endocrinology Reviews 2004; 2(S2): 249-255.

5. Cappellini MD, Cohen A, Porter J, Taher A, Viprakasit V. Guidelines for the management of transfusion dependent thalassaemia. Thalassaemia international federation 2014; publication no. 20: 3rd edition. 
6. Wonke B, De Sanctis V. Clinical aspects of transfusional iron overload. Clin Exp Hematol 2001; 12:322-34.

7. Soliman AT, Khalafallah H, Ashour R. Growth and factors affecting it in thalassemia major. Hemoglobin 2009;33:S116-26.

8. Malik SA, Syed S, Ahmed N. Frequency of hypothyroidism in patients of beta-thalassaemia. $\mathrm{J}$ Pak Med Assoc 2010 Jan; 60(1):17-20.

9. De Sanctis V1, De Sanctis E, Ricchieri P, Gubellini E, Gilli G, Gamberini MR. Mild subclinical hypothyroidism in thalassaemia major: prevalence, multigated radionuclide test, clinical and laboratory long-term follow-up study. Pediatr Endocrinol Rev 2008 Oct; 6 Suppl 1:174-80.

10. Vincenzo De Sanctis, Ashraf T. Soliman, Heba Elsedfy, et al. Growth and endocrine disorders in thalassemia: The international network on endocrine complications in thalassemia (I-CET) position statement and guidelines.

11. Hershko C, Link G, Cabantchik I. Pathophysiology of iron overload. Ann N Y Acad Sci 1998; 30:191-201.

12. De Sanctis V, Vullo C, Bagni B, Chiccoli L. Hypoparathyroidism in beta-thalassemia major. Clinical and laboratory observations in 24 patients. Acta Haematol 1992; 88:105-8.

13. Tiosano D, Hochberg Z. Endocrine Complications of Thalassaemia, Journal of Endocrinological Investigation 2001; 24:716-723.

14. Angelopoulos NG, Zervas A, Livadas S, et al. Reduced insulin secretion in normoglycaemic patients with beta-thalassaemia major. Diabetic Medicine 2006; 23(12):1327-31.

15. Monge L, Pinach S, Caramellino L, Bertero MT, Dall'omo A, Carta Q. The possible role of autoimmunity in the pathogenesis of diabetes in B-thalassemia major. Diabetes and Metabolism 2001; 27(2):149-54.

16. Poomthavorn $\mathrm{P}$, Isaradisaikul $\mathrm{B}$, Chuansumrit $\mathrm{A}$, Khlairit P, Sriphrapradang A, Mahachoklertwattana P. High prevalence of "biochemical" adrenal insufficiency in thalassemics: Is it a matter of different testings or decreased cortisol binding globulin? J Clin Endocrinol Metab 2010; 95:4609-15.

17. Elsedfy HH, El Kholy M, Tarif R, Hamed A, Elalfy M. Adrenal function in thalassemia major adolescents. Pediatr Endocrinol Rev 2011; 8:2959.

18. Rashid H. Merchant, Amruta Shirodkar, Javed Ahmed. Evaluation of Growth, Puberty and
Endocrine Dysfunctions in Relation to Iron Overload in Multi Transfused Indian Thalassemia Patients. The Indian Journal of Pediatrics June 2011; Vol. 78, Issue 6, pp 679-683.

19. Sasima Srisukh, Boonsong Ongphiphadhanakul, Pongamorn Bunnag. Hypogonadism in thalassemia major patients. Journal of Clinical \& Translational Endocrinology September 2016; vol. 5, Pages 42-45.

20. Lassman MN, O’Brien RT, Pearson HA, Wise JK, Donabedian RK and Felia P. Endocrine Evaluation in Thalassemia Major. Annals of the New York Academy of Science 1974; Vol. 232, pp. 226-237.

21. Chatterjee R, Katz M, Cox TF and Porter JB. Prospective Study of the Hypothalamic Pituitary Axis in the Thalassemic Patients Who Developed Secondary Amenorrhea. Clinical Endocrinology 1993; Vol. 39, pp. 287- 296.

22. Anoussakis $\mathrm{CH}$, Alexiou D, Abatzis D and Bechrakis G. Endocrinological Investigation of Pituitary Gonadal Axis in Thalassemia Major. Acta Paediatrica Scandinavia 1977; Vol. 66, No. 1, pp. 49-51.

23. Landau H, Spitz IM, Civadilli G and Rachmilewitz EA. Gonadotropin, Thyrotropin and Prolactin Reserve in Beta Thalassemia. Clinical Endocrinology 1978; Vol. 9, pp. 163-173.

24. Kletzky OA, Cossin G, Marrs RP, Bernstein G, March CM and Mishell Jr GM. Gonadotropin Insufficiency in Patients with Thalassemia Major. Journal of Clinical Endocrinology and Metabolism 1979; Vol. 48, No. 6, pp. 901-905.

25. Raiola G, Galati MC, De Sanctis V, Caruso Nicoletti M, Pintor C, De Simone M, et al. Growth and puberty in thalassemia major. J Pediatr Endocrinol Metab 2003;16:259-6. 